Association for Information Systems AIS Electronic Library (AISeL)

ICIS 1989 Proceedings

International Conference on Information Systems

1989

\title{
THE ECOLOGY OF MIS RESEARCH: A TWENTY YEAR STATUS REVIEW
}

Maryam Alavi

University of Maryland, College Park

Patricia Carlson

University of Minnesota

Geoffrey Brooke

University of Minnesota

Follow this and additional works at: http://aisel.aisnet.org/icis 1989

\section{Recommended Citation}

Alavi, Maryam; Carlson, Patricia; and Brooke, Geoffrey, "THE ECOLOGY OF MIS RESEARCH: A TWENTY YEAR STATUS REVIEW" (1989). ICIS 1989 Proceedings. 6.

http://aisel.aisnet.org/icis1989/6 


\title{
THE ECOLOGY OF MIS RESEARCH: A TWENTY YEAR STATUS REVIEW
}

\author{
Maryam Alavi \\ College of Business and Management \\ University of Maryland, College Park \\ Patricia Carlson \\ Geoffrey Brooke \\ Carlson School of Management \\ University of Minnesota
}

\begin{abstract}
The debate concerning the legitimacy of MIS as a field of research has endured over the last decade. The absence of theories and lack of a cumulative research tradition have been areas of particular concern. The research reported in this article provides evidence on these important issues. The study systematically analyzed MIS articles in seven core journals over the period 1968-1988. The resulting database, consisting of 792 articles, was analyzed for themes and topics, and on the basis of type of article (empirical/non-empirical). The findings indicate that MIS research efforts have refocused in some areas, while much remains to be done in others. This study provides the opportunity to pause and reflect on the last twenty years of research in MIS and to take stock so that the research of the coming twenty years will extend and build upon the existing foundations.
\end{abstract}

\section{INTRODUCTION}

A decade ago, the First International Conference on Information Systems focused on the challenges of MIS research. In a paper presented at this first conference, Peter Keen (1980) stated,
At present, MIS research is a theme rather than a substantive field. Luckily, since computers are important and know- ledge of how to use them limited, acade- mics have been given a line of credit to draw on.

Keen and other scholars expressed concern about absence of MIS theories, incoherence of the field, and the lack of a cumulative tradition of research. A decade later, at the Tenth International Conference on Information Systems, it is timely to assess the progress of MIS as a field of research and inquiry and to examine its intellectual development and maturity. The current study addresses these issues through a systematic examination and analysis of 792 MIS articles published in seven core MIS journals in the 1968-1988 time period.

The importance of the current study for the still evolving field of MIS lies mainly in that it provides an opportunity to pause and reflect upon both what has been accomplished by past work and what needs to be accomplished in the future. As such it might promote informed discussion and debate and thereby help researchers direct their efforts in the most productive manner. Even emerging fields such as MIS have a sense of history; those who cut themselves off from curiosity and reflection are likely to atrophy (Keen 1980).

\section{BACKGROUND}

The present study was initiated in June, 1988, at the International Center for Information Technologies (ICIT) to examine the evolution of MIS research and epistemology. The primary objective of the project was to develop an overview of the intellectual structure of MIS through direct and systematic analysis of a sample of mainstream MIS articles published to date. The project aimed at studying what constitutes MIS research through examining topics, themes and research strategies in the literature. This would establish a benchmark for tracking the status of MIS development and evolution which would shape and advance the field as well as focus attention on areas requiring more research.

As fields of research or professional practice evolve, they become objects of interest and study themselves (Elam, Huber, and Hurt 1986). For example, Harvard Business School's 1984 Research Colloquium on Information Systems was devoted to highlighting the research needs of MIS. Furthermore, several studies published during the last decade have reviewed and examined different aspects of the MIS field. Ives, Hamilton, and Davis (1980) developed a comprehensive taxonomy of potential MIS research areas and used it to classify over 300 MIS doctoral dissertations. Ives and Olson (1984) examined research associated with user involvement in the MIS development process. Jarvenpaa, Dickson, and DeSanctis 
(1985) addressed methodological issues in experimental research. Culnan (1986) conducted a co-citation analysis of the MIS literature from 1972 to 1982 in order to identify intellectual subfields in MIS and the reference disciplines within which these subfields are founded. Culnan and Swanson (1986) examined published articles from 1980 to 1984 to evaluate the emergence of MIS as an independent scholarly field of study, differentiated from reference disciplines such as computer science, management science, and organization behavior. Elam, Huber and Hurt (1986) analyzed DSS literature between 1975 and 1985 in order to identify trends in research methodology, topics and application areas. Farhoomand (1987) studied the evolution of MIS from a philosophical scientific perspective through examination of published articles in the 1977 to 1985 period. Alavi and Joachimsthaler (1988) conducted a meta-analytic review of DSS and individual differences literature published between 1978 and 1988 in order to synthesize and integrate the empirical findings in this area.

The present work builds upon and extends the breadth and depth of the previous studies. For example, in the present study the scope of MIS literature coverage is extended to cover a twenty-year time period from 1968 to 1988. Furthermore, instead of being confined to a specific topic or theme (DSS, GDSS, or implementation) or a specific type of research (field studies or laboratory experiments), the current study adopted a comprehensive perspective and incorporated research pertaining to any of the environmental, system or process aspects of MIS.

\section{METHODOLOGY}

Seven journals were selected to be included in the study: Communications of the ACM, Data Base, Decision Sciences, Harvard Business Review, Management Science, MIS Quarterly, and Sloan Management Review.

The MIS articles published in these journals between 1968 and 1988 were collected and analyzed. For an article to be included in the study, it had to address an aspect of research, management, design, implementation, operation, use or impact of MIS or MIS components. The MIS field draws on several reference disciplines such as computer science, management science, cognitive science, and organizational behavior. Some articles focusing on issues of interest to these disciplines could be considered part of the MIS literature at some level of abstraction. However, such articles were not included in the study unless they were explicitly related to at least one of the above MIS topics.

The Naisbitt Group (1982), after reviewing and analyzing a large number of newspapers in different communities, observed that most of the new social phenomena and trends occur in certain "bellwether" communities as reflected in their newspaper. Thus, it was felt that analysis of a number of bellwether MIS journals would provide a good understanding of the priorities and issues of interest to the MIS community. The seven journals selected for this study were included in the list of journal preferences of MIS academicians and practitioners for publishing their work (Hamilton and Ives 1982). It was felt that articles in these journals represent a good mix of MIS scholarly work (those published in Management Science, the theory and research section of the MIS Quarterly, and Decision Sciences) and practitioner oriented work (those appearing in Harvard Business Review, the application section of the MIS Quarterly, and Sloan Management Review). Furthermore, these journals were included in all of the previous MIS literature reviews (Elam, Huber, and Hurt 1986; Vogel and Wetherbe 1984; Culnan 1986). As such it was felt that they represent the mainstream of MIS work. All the journals were published in the United States and had been in publication for at least ten years during the time period 1968 to $1988 .{ }^{1}$

\section{ANALYSIS}

The journal articles included in the study were classified and coded in two ways:

1. By subject or topic according to the keyword classification scheme of Barki, Rivard, and Talbot (1988).

2. By type according to a framework developed specifically for the study.

After examining some of the existing keyword classification schemes (MIS Quarterly and Computing Review), the Barki-Rivard-Talbot classification scheme was adopted and used to code the topic or subject areas addressed by the articles. It was determined that this scheme presents the most comprehensive and current approach to classification of the MIS territory. This classification contains over 1,100 keywords and consists of nine top-level categories (displayed in Table 1), each of which is divided into several subcategories.

Table 1. Top-Level Categories of Barki-Rivard-Talbot MIS Classification Scheme $(1988$, p. 300)

\begin{tabular}{ll}
\hline Code & \multicolumn{1}{c}{ Categories } \\
\hline & Reference Disciplines \\
$\mathrm{A}$ & External Environment \\
$\mathrm{B}$ & Technological Environment \\
$\mathrm{C}$ & Organizational Environment \\
$\mathrm{D}$ & IS Management \\
$\mathrm{E}$ & IS Development and Operations \\
$\mathrm{F}$ & IS Usage \\
$\mathrm{G}$ & Information Systems \\
$\mathrm{H}$ & IS Education and Research \\
\hline
\end{tabular}

The framework developed for classifying the articles by type is displayed in Figure 1. This framework is consistent 
with the existing MIS methodological taxonomies (Vogel and Wetherbe 1984; Van Horn 1973) and extends them. At the highest level, the framework distinguishes between empirical and non-empirical articles. The empirical articles capture the essence of research by relying on observation (Van Horn 1973). The empirical articles are further divided into those that describe an object (e.g., an information system) which endures through time, and those that describe an event or process (e.g., a development project) which has a limited life span or which is essentially a temporary phenomenon. Empirical articles focusing on objects may describe a system, product, installation or company MIS function; or they may contain descriptions of types or classes of products, technologies, systems, and projects. Empirical articles focusing on events and processes may take a number of methodological research approaches (lab experimentation, field experimentation, case study) or they may involve development of MIS instruments (user satisfaction questionnaire) and design methodologies.
Non-empirical articles are those that are primarily based on ideas, frameworks, and speculation rather than on observation. Non-empirical articles may contain some empirical observations or data, but these will be in a secondary or supporting role only. That is, the emphasis is on ideas rather than on data and observations. Nonempirical articles may be divided into three categories: conceptual, illustrative and mixed. Conceptual articles describe frameworks, models or theories. These articles do not aim to directly guide practice, but to explore reasons and to offer explanations. Illustrative articles are intended to guide practice, often containing recommendations for action or steps to be followed in given circumstances; the stress is on "what" or "how" rather than "why." Mixed articles are those that have an approximately equal emphasis on conceptual and illustrative elements.

A more detailed description of the classification scheme (displayed in Figure 1) and two examples of each article type is provided in Appendix A.

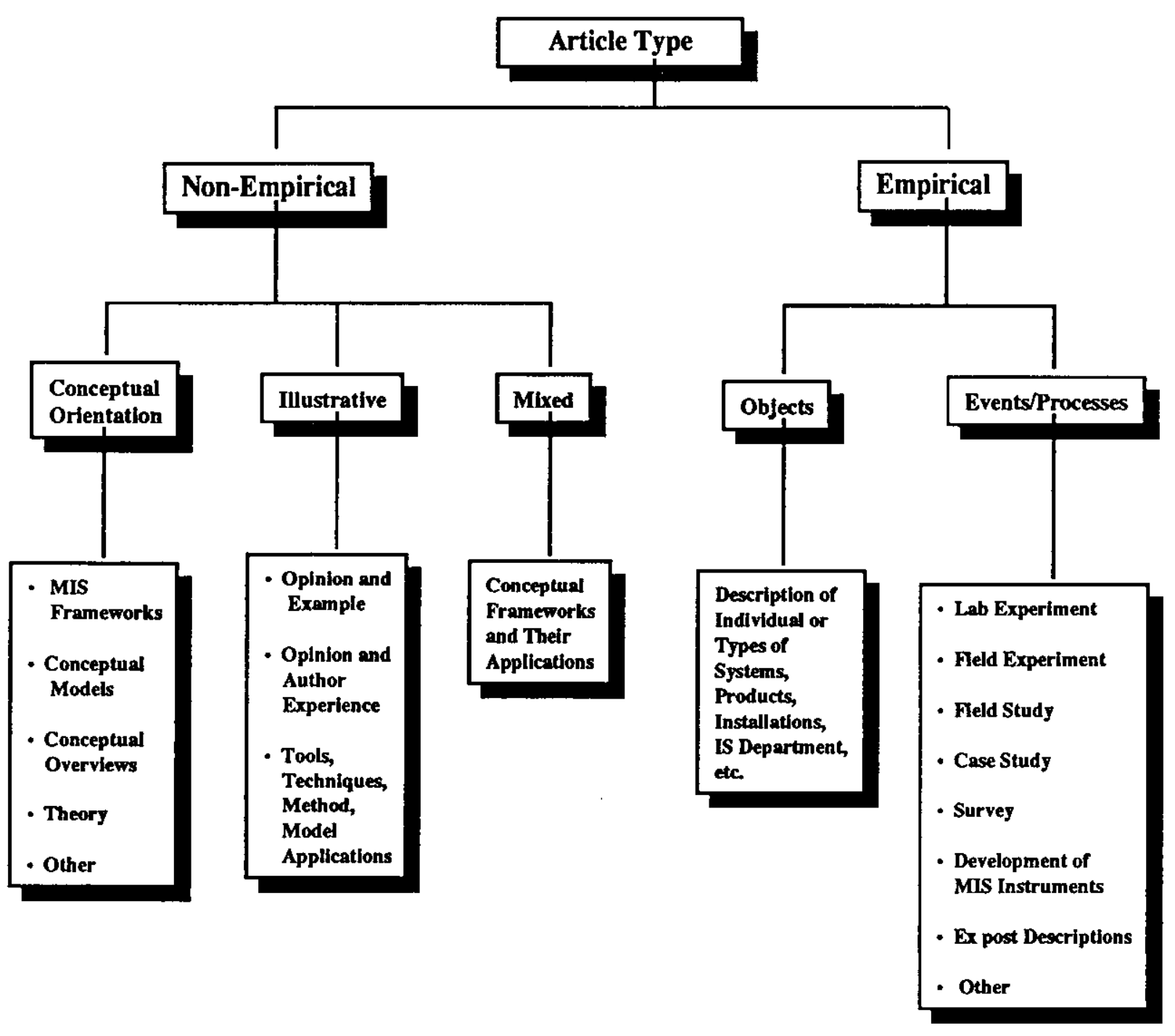

Figure 1. A Framework for Classification of MIS Articles by Type 
Table 2. Frequency of MIS Articles in the Journals by Three-Year Intervals

\begin{tabular}{|c|c|c|c|c|c|c|c|c|}
\hline Journals & 1968-70 & $1971-73$ & $1974-76$ & $1977-79$ & $1980-82$ & 1983-85 & $1986-88$ & Total \\
\hline Communications of the $A C M$ & 4 & 12 & 7 & 21 & 20 & 42 & 31 & 137 \\
\hline Data Base & 2 & 17 & 6 & 16 & 23 & 32 & 36 & 132 \\
\hline Decision Science & 1 & 1 & 8 & 5 & 7 & 8 & 13 & 43 \\
\hline Harvard Business Review & 19 & 11 & 11 & 6 & 19 & 19 & 10 & 95 \\
\hline MIS Quarterly* & 0 & 0 & 0 & 50 & 64 & 64 & 74 & 252 \\
\hline Management Science & 9 & 6 & 8 & 11 & 12 & 13 & 10 & 69 \\
\hline Sloan Management Review & 2 & 12 & 9 & 6 & 6 & 14 & 15 & 64 \\
\hline Total by 3-year intervals & 37 & 59 & 49 & 115 & 151 & 192 & 189 & 792 \\
\hline
\end{tabular}

*MIS Quarterly started publication in 1977.

\section{PROCEDURE}

Two of the researchers were involved in coding the articles and worked independently according to the following procedures. The entire collection of the MIS Quarterly for the time period covered by the study was included. For the six remaining journals (Communications of the $A C M$, Data Base, Decision Sciences, Harvard Business Review, Management Science, and Sloan Management Review), the tables of contents were examined by the coders in order to identify the MIS related titles. The search was based on the presence of certain keywords including management, information, computer, data, and system. The tables of contents were then reviewed for recognized MIS authors to identify MIS articles that might have been missed by examining the article titles alone. The lists of articles identified by each individual coder were pooled to establish a master list. The text of each article in the list was then reviewed in order to exclude articles that might have contained MIS-related keywords in the title but essentially had a non-MIS focus.

Once it was determined to include an article in the study, a coding sheet (see Appendix B) was used to record data extracted from the articles in order to provide uniformity, consistency and completeness of data collection. To ensure thoroughness, a short summary was written ${ }^{2}$ and the article was coded according to the two classification schemes: the classification scheme for article type shown in Figure 1 and the Barki-Rivard-Talbot scheme. Each article was assigned to only one of the classifications shown in Figure 1 ; however, depending on the number of topics covered in the article, one or more Barki codes were assigned (refer to the coding sheet in Appendix B). In all, 1,452 Barki codes were assigned to the 792 articles, an average of 1.83 codes per article. The coding sheets were then used to input the data into a dBase III Plus database to facilitate data manipulation and analysis. On the average, each article took about 20 minutes to code. ${ }^{3}$

\section{RESULTS}

A total of 792 articles was identified and coded using the above procedures. The numbers of articles by journal and three-year interval are shown in Table 2. As far as nonMIS journals are concerned, 159 articles were published in the practitioner oriented journals (Harvard Business Review and Sloan Management Review) and 112 articles were published in scholarly journals (Decision Sciences and Management Science). As expected, the journals dedicated to MIS or computing and data processing (MIS Quarterly, Communications of the $A C M$, and Data Base) provide close to two-thirds of the publications ( 65.7 percent). The highest number of articles has been published by MIS Quarterly, followed by the Communications of the $A C M$, and Data Base respectively.

\subsection{Publication Topics}

Articles classified in different topic areas of the BarkiRivard-Talbot classification scheme (one-letter categories A-I) by three-year interval are displayed in Table 3. In the past two decades, the most extensively researched topics in our sample were IS management followed by information systems, and IS development and operations. The specific research issues of interest in each of these three topic areas are shown in Table 4.

In the area of IS management (category E), the three most popular topics were IS evaluation (user satisfaction and cost-benefit analysis), IS planning (IS strategic planning issues), and IS management issues (stage theory). In the information systems area (category $\mathrm{H}$ ), the highest number of articles were written on the topic of information systems types (particularly DSS and expert systems). The next two popular topics in this area were IS applications and IS characteristics. The highest numbers of articles in the IS application area were related to simulation and modeling, government, and banking applications. In the IS characteristics area, the main topic of interest has been system interface characteristics, particularly graphics interfaces.

The issues of interest pertinent to category F (IS development and operations) consisted of IS life cycle activities (information requirements analysis and IS design), IS development strategies (prototyping and participative design), and IS implementation (user-analyst differences). 
Table 3. Article Codes in Different Topical Areas by Three-Year Intervals

\begin{tabular}{|c|c|c|c|c|c|c|c|c|c|}
\hline $\begin{array}{l}\text { Barki-Rivard- } \\
\text { Talbot Code }\end{array}$ & Topic Areas & $1968-70$ & 1971-73 & 1974-76 & 1977.79 & $1980-82$ & 1983-85 & $1986-88$ & Total \\
\hline $\mathbf{E}$ & IS Management & 16 & 20 & 16 & 50 & 60 & 99 & 77 & 338 \\
\hline $\mathbf{H}$ & Information Systems & 16 & 25 & 13 & 31 & 48 & 46 & 66 & 245 \\
\hline $\mathbf{F}$ & IS Development and Operations & 1 & 5 & 10 & 46 & 40 & 54 & 39 & 195 \\
\hline $\mathbf{A}$ & Reference Disciplines & 5 & 14 & 15 & 18 & 25 & 28 & 41 & 146 \\
\hline G & IS Usage & 5 & 1 & 3 & 10 & 12 & 22 & 41 & 94 \\
\hline 1 & IS Education and Research & 2 & 10 & 4 & 9 & 17 & 11 & 20 & 73 \\
\hline D & Organizational Environment & 2 & 4 & 2 & 9 & 17 & 20 & 19 & 73 \\
\hline $\mathrm{C}$ & Technical Environment & 1 & 4 & 3 & 4 & 5 & 17 & 15 & 49 \\
\hline $\mathbf{B}$ & External Environment & 3 & 3 & 6 & 7 & 3 & 9 & 3 & 34 \\
\hline & & & & & & & & & 1247 \\
\hline
\end{tabular}

NOTE: To avoid double counting, the articles which were assigned multiple codes in the same major category are counted only once per category. For example, an article with codes FA03, FB03 and HA03 is counted once in IS Development and Operations (category F) and once in Information Systems (category H). For this reason, the total number of codes in the table $(1,247)$ is different from the total number of codes assigned in the study $(1,452)$. The difference represents those articles which had more than one code in a single major category.

Table 4. Most Popular Research Issues in the Top Three Topic Areas of MIS Research

\begin{tabular}{|c|c|c|}
\hline $\begin{array}{l}\text { Barki-Rivard-Talbot } \\
\text { Classification Codes }\end{array}$ & Description & $\begin{array}{c}\text { Number of } \\
\text { Published Articles }\end{array}$ \\
\hline $\begin{array}{ll}\mathrm{EJ} \\
\mathrm{EG} \\
\mathrm{EM}\end{array}$ & $\begin{array}{l}\text { IS Management } \\
\text { IS evaluation } \\
\text { IS planning } \\
\text { IS management }\end{array}$ & $\begin{array}{r}115 \\
64 \\
61\end{array}$ \\
\hline $\begin{array}{l}\text { HB } \\
\text { HD }\end{array}$ & $\begin{array}{l}\text { Information Systems } \\
\text { Types of information } \\
\text { systems } \\
\text { IS application areas } \\
\text { IS characteristics }\end{array}$ & $\begin{array}{r}100 \\
40\end{array}$ \\
\hline $\begin{array}{l}\text { FB } \\
\text { FA } \\
\text { FD }\end{array}$ & $\begin{array}{l}\text { IS Development and } \\
\text { Operations } \\
\text { IS life cycle activities } \\
\text { IS development } \\
\text { strategies } \\
\text { IS implementation }\end{array}$ & $\begin{array}{l}85 \\
57\end{array}$ \\
\hline
\end{tabular}

The data displayed in Table 3 indicates that the smallest number of articles in the time period 1968 to 1988 were in the topic areas of external environment (category B), technological environment (category C), and organization. al environment (category D). The focus of past research in the area of the external environment has been primarily on the economic, social, and legal environments. The articles dealing with the technological environment have primarily addressed database management systems and different aspects of computer hardware systems. Notice that the number of technological articles has tripled from time period 1980-82 to $1983-85$. The articles published in category D (organizational environment) were primarily focused on organizational structure. The number of published articles addressing the organizational environment issues more than doubled in the early 1980s compared to the late 1970 s.

\subsection{Article Types}

The number of articles by article type and three-year time interval is displayed in Figure 2. For all the three-year time intervals between 1968 and 1985, the number of nonempirical articles was greater than the number of empirical articles. Overall, the empirical articles constituted 46.5 percent of the total published between 1968 and 1988. The frequencies of the types of non-empirical articles (conceptual, illustrative, and mixed) are displayed in Table 5. With the exception of a peak in the time period 1971 to 1973 , the number of conceptual articles (MIS frameworks, conceptual models and theories) has been consistently lower than the number of illustrative articles. A total of 19 mixed articles were identified. In the empirical articles, shown in Table 6, the most popular research methodologies between 1968 and 1988 were field studies (used in 122 articles or 33 percent of the sample) followed by laboratory experiments (used in 57 or 15.4 percent of the sample). Case studies ${ }^{4}$ accounted for 9.7 percent of the empirical articles (a total of 36 articles). Only 4.3 percent of the empirical articles (16 articles) used field experimentation in the period 1968 to 1988 . Descriptions of types of products and technologies and of specific systems, products, and installations accounted for 78 (21.1 percent) of the empirical articles written during this time period.

The number of articles by type and by research topic (Barki-Rivard-Talbot categories A-I) are displayed in Figure 3. Interestingly, both empirical and non-empirical articles have primarily focused on the same topics: IS management (category $E$ ), information systems (category $\mathrm{H}$ ), development and operations (category F), and reference disciplines (category $\mathrm{A}$ ). The smallest numbers of empirical articles appeared in category B (external environment) and category I (IS education and research) with 11 and 14 articles respectively. The smallest number of nonempirical articles (19 articles) was published in the area of technological environment (computer systems and software). Approximately the same numbers of empirical and 


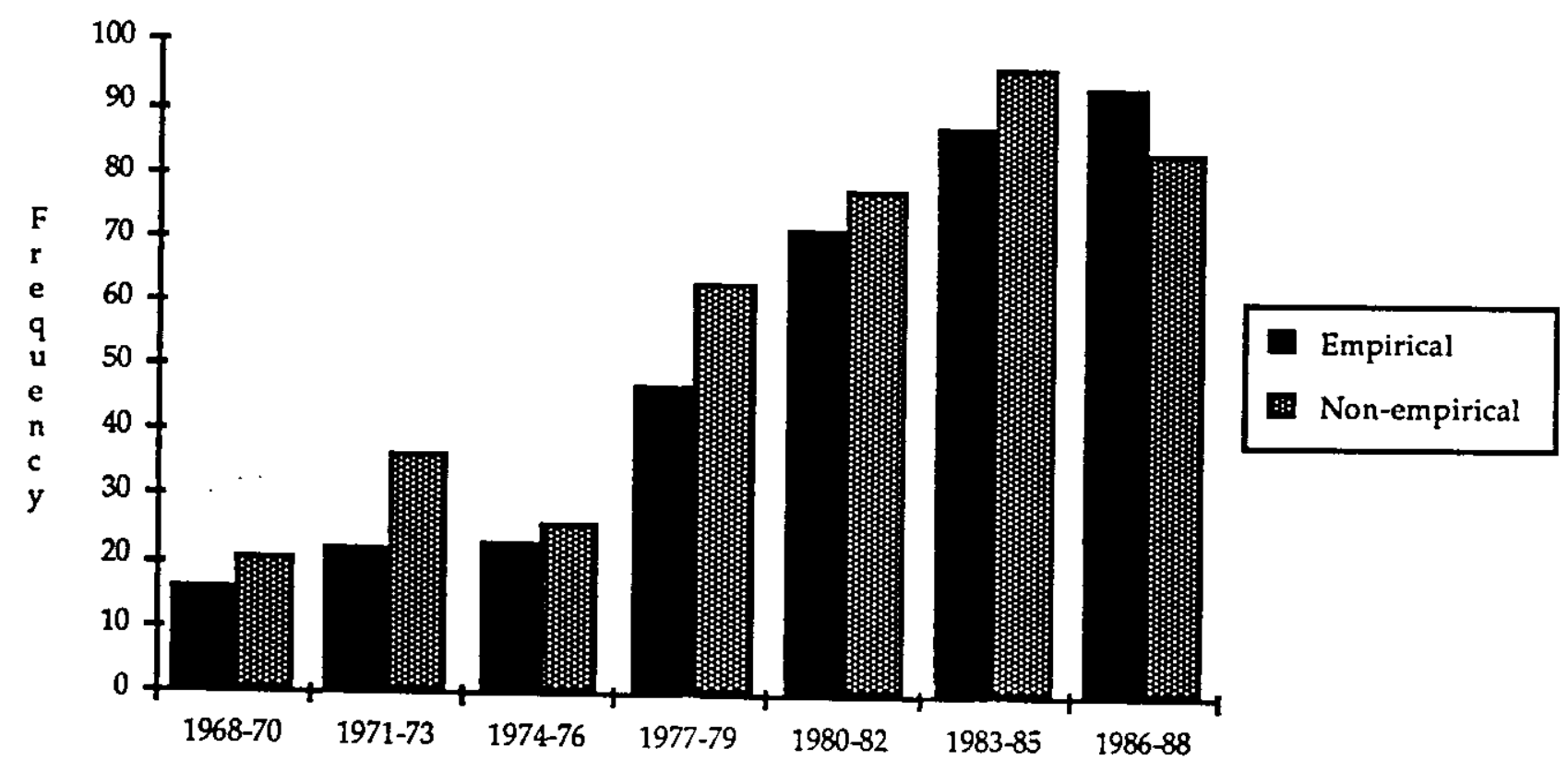

Figure 2. Number of Articles by Type and Year

Table 5. Number of Non-Empirical Articles by Type and Three-Year Time Periods

\begin{tabular}{lrrrrrrrr}
\hline Non-Empirical Articles & $1968-70$ & $\mathbf{1 9 7 1 - 7 3}$ & $\mathbf{1 9 7 4 - 7 5}$ & $\mathbf{1 9 7 7 - 7 9}$ & $\mathbf{1 9 8 0 - 8 2}$ & $\mathbf{1 9 8 3 - 8 5}$ & $\mathbf{1 9 8 6 - 8 8}$ & Total \\
\hline Conceptual articles & 1 & 24 & 9 & 22 & 29 & 23 & 38 & 146 \\
Illustrative articles & 20 & 13 & 17 & 42 & 47 & 70 & 49 & 258 \\
Mixed articles & 0 & 0 & 0 & 2 & 5 & 7 & 5 & 19 \\
TOTAL & & & & & & & 423 & \\
\hline
\end{tabular}

Table 6. Empirical Articles by Type (1968-1988)

\begin{tabular}{lc}
\hline & $\begin{array}{l}\text { Number of } \\
\text { Articles }\end{array}$ \\
Research Strategy & \\
Field study & 122 \\
Lab experiment & 57 \\
Case studies & 36 \\
Survey & 30 \\
Field experiment & 16 \\
& \\
Other Empirical Type & 78 \\
Description & 16 \\
Ex post description & 8 \\
Development of tool & 6 \\
Other & 369 \\
TOTAL & \\
\hline
\end{tabular}

non-empirical articles were published in the topic areas of reference disciplines (category A) and IS development and operations (category F). Relative to empirical articles, a larger number of non-empirical articles (196 versus 143 articles) focused on IS management (category E). On the other hand, more empirical articles addressed the topic of information systems (category $\mathbf{H}$ ) primarily due to the relatively large number of empirical articles in the area of user-system interface.

\section{DISCUSSION AND CONCLUSION}

By collecting and analyzing MIS literature published in "bellwether" journals in the period 1968 to 1988 , we have been able to paint an overall picture of the MIS field and its evolution as represented in this literature.

Our analysis indicated that MIS has been closely associated with practice. Two-hundred fifty articles (approximately one third of all articles published in the period 1968 to 1988) have been devoted to describing and illustrating how the MIS concepts and models could be applied. In fact, relative to purely conceptual/theoretical articles, approximately twice as many illustrative and applied articles have been published in the literature during the past two decades. Furthermore, during the early years of MIS (1968 to 1973) twice as many articles were published in the practitioner oriented journals (Harvard Business Review 


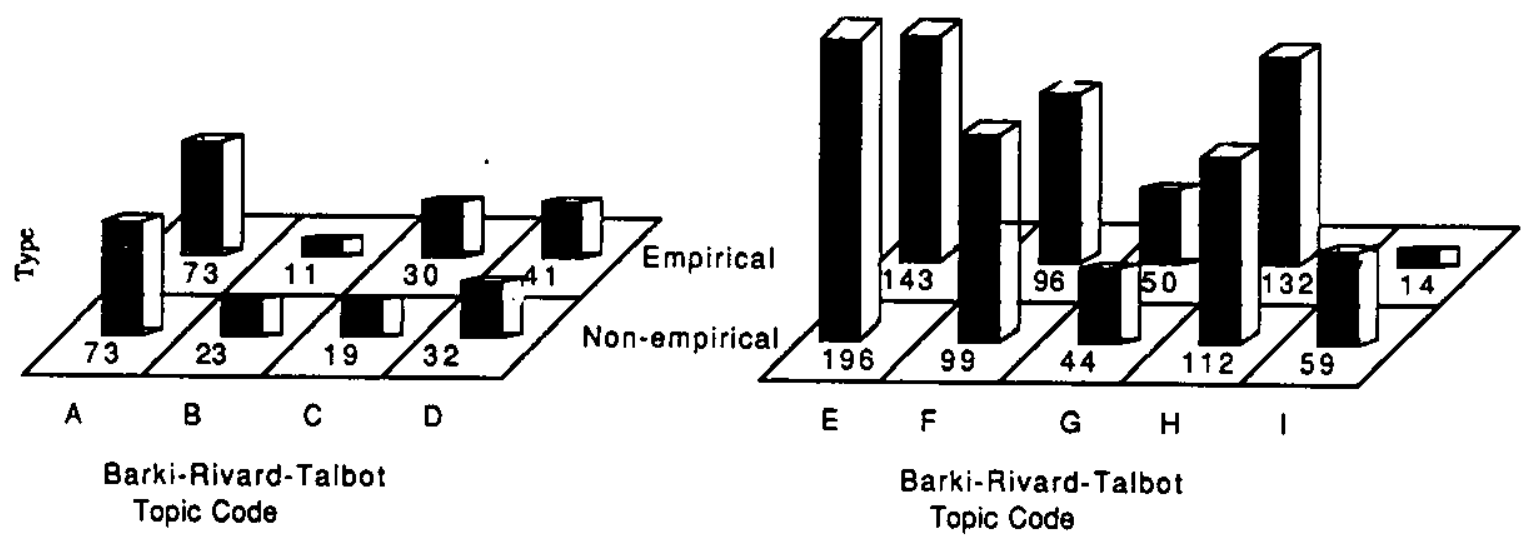

Figure 3. Articles by Topic and Type

and Sloan Management Review) as compared to the number of articles published in academic and scholarly journals (Decision Sciences and Management Science).

An analysis of the topic areas covered by the articles indicated a dearth of published work on the topics of external environment (economic, legal, social and political environments), technological environment (hardware and software) and organizational environment (organization dynamics, structure and task characteristics). The small number of technological articles represented in the sample may be attributed to the management orientation of the journals included in the study. On the other hand, the research emphasis on the external and organizational environments should be increased. In our opinion, as information systems become more prevalent in organizations and societies, more work on these topics is needed to move the field forward by providing feedback and guiding practice and further research.

Our research reveals a healthy sign in the evolution of the MIS field. Since the mid-1980s there has been a refocusing of the MIS research efforts. For the first time during the past two decades, the number of empirical articles exceeded the number of non-empirical articles essentially focusing on purely conceptual work. This may indicate that the latter type of article was appropriate in the early years of MIS, but with the maturity of the field, there has been a redirecting and refocusing of the research effort paralleled by changes in the publishing standards and practices of core MIS journals. Empirical research articles involving case studies, laboratory experimentation, and field studies have been on the rise during the past twenty years. In particular, the popularity of the laboratory experimentation suggests that an effort is being made to focus on testing theories and/or to construct empirically based theories. However, the small numbers of theoretically oriented articles (only 15 in the entire sample) raises questions about the rate of progress in the area. We find the paucity of MIS oriented theories alarming because of the potential implications for quality, experimental design and value of MIS research. Baroudi and Orlikowski (1986) have reported problems with MIS empirical work. They suggest that the average power (the ability to detect treatment effects) of much of the MIS empirical work is low. In the absence of MIS theories, this can result in important relationships among variables going undetected. In a survey of MIS publications by Jenkins (1985), it was concluded that only one-third of the studies chose the appropriate research methodology. Theories are needed to guide research and choice of research methodologies. The impact and role of theories and theoretical views on the choice of research methodologies are addressed by Kling (1980) and Weick (1984).

Almost all of the research methodologies employed in the articles included in the study can be characterized as traditional methodologies patterned after research in the natural sciences. These traditional methods may not be sufficient for addressing all of the important MIS issues. For example, Vitalari (1985) states that longitudinal research strategies are needed to examine time-dependent phenomena such as adaptation and learning. Furthermore, some authors have suggested some potential problems associated with using the natural sciences paradigm for MIS research. For example, Cooper (1987) and Klein and Lyytinen (1985) suggest that IS development, as a primarily technical artifact, leads to misinformation system due to ignoring the subjective and intersubjective dimensions of the creation of meaning and knowledge in a social action case. Thus, methodological pluralism, allowing multiple paradigms for MIS research (e.g., methods from the natural as well as the social sciences) should be encouraged (Cooper 1987; Hirschheim 1985). Examples of new approaches that may complement the traditional natural scientific tradition are offered by Galliers (1985) and 
include futures research (Nilles, Mohrman, and El Sawy 1983), phenomenological research (Boland 1985), and action research (Wood-Harper 1985).

In our assessment, the MIS field has accumulated a substantial research literature base during the past two decades. This research base provides a valuable and significant source of knowledge for researchers and practitioners in the field. The field has taken major steps toward establishing a cumulative tradition of research necessary for providing scientific and valid guidelines for practice and research. Much work remains to be done. We hope this paper and our assessment is helpful in stimulating discussion and focusing attention on the direction that the future should take.

\section{ACKNOWLEDGEMENTS}

This research was supported by a grant from the International Center for Information Technologies, Washington, D. C., Peter G. W. Keen, Executive Director.

\section{REFERENCES}

Alavi, M., and Joachimsthaler, E. "A Meta-Analytic Review of DSS - Individual Differences Literature: What Have We Learned?" Working Paper, ISRC, College of Business, University of Houston, Houston, Texas, 1988.

Barki, H.; Rivard, S.; and Talbot, J. "An Information Systems Keyword Classification Scheme." MIS Quarterly, Volume 34, June 1988, pp. 299-322.

Baroudi, J. J., and Orlikowski, W. J. "Misinformation in MIS Research: The Problem of Statistical Power." Working Paper CRIS 125, Center for Research on Information Systems, Graduate School of Business Administration, New York University, June 1986.

Boland, R. J. "Phenomenology: A Preferred Approach to Research on Information Systems." In E. Mumford et al., Editors, Research Methods in Information Systems, New York: North Holland, 1985, pp. 193-202.

Cooper, R. B. "Review of Management Information Systems Research, A Management Support Emphasis." Working Paper, Graduate School of Business, The University of Michigan, 1987.

Culnan, M. "The Intellectual Development of Management Information Systems, 1972-1982: A Co-Citation Analysis." Management Science, Volume 32, Number 2, 1986, pp. 156-172.

Culnan, M., and Swanson, E. B. "Research in Management Information Systems, 1980-1984: Points of Work and
Reference." MIS Quarterly, Volume 32, Number 9, 1986, pp. 289-301.

Elam, J. J.; Huber, G. P.; and Hurt, M. E. "An Examination of the DSS Literature (1975-1985)." In E. R. McLean and H. G. Sol, Editors, Decision Support Systems: $A$ Decade in Perspective, 1986, pp. 1-17.

Farhoomand, A. "Scientific Progress of Management Information Systems." Data Base, Summer 1987, pp. 4856.

Galliers, R. D. "In Search of a Paradigm for Information Systems Research." In E. Mumford et al., Editors, Research Methods in Information Systems, New York: North Holland, 1985, pp. 281-297.

Hamilton, S., and Ives, B. "Knowledge Utilization among MIS Researchers." MIS Quarterly, Volume 6, Number 4, 1982, pp. 61-77.

Hirschheim, R. A. "Information Systems Epistemology: A Historical Perspective." In E. Mumford et al., Editors, Research Methods in Information Systems, North Holland, New York, 1985, pp. 13-36.

Ives, B.; Hamilton, S.; and Davis, G. "A Framework for Research in Computer-Based Management Information Systems." Management Science, Volume 26, Number 9, 1980, pp. 910-934.

Ives, B., and Olson, L. H. "User Involvement and MIS Success: A Review of Research." Management Science, Volume 30, Number 7, 1984, pp. 586-603.

Jarvenpaa, S. L.; Dickson, G. W.; and DeSanctis, G. "Methodological Issues in Experimental IS Research: Experiences and Recommendations." MIS Quarterly, Volume 2, Number 3, 1988, pp. 141-156.

Jenkins, A. M. "Research Methodologies and MIS Research." In E. Mumford et al., Editors, Researcher Methods in Information Systems, New York: North Holland, 1985, pp. 103-117.

Keen, P. G. W. "MIS Research: Reference Disciplines and Cumulative Traditions." Proceedings of the First International Conference on Information Systems, Philadelphia, Pennsylvania, December 1980, pp. 8-18.

Klein, H. K., and Lyytinen, K. "The Poverty of Scientism in Information Systems." In E. Mumford et al., Editors, Research Methods in Information Systems, New York: North Holland, 1985, pp. 131-161.

Kling, R. "Social Analysis of Computing: Theoretical Perspectives in Recent Empirical Research." Computing Surveys, Volume 12, 1980, pp. 61-110. 
Naisbitt, J. Megatrends, New York: Warner Books, 1982.

Nilles, J.; Mohrman, A.; and El Sawy, O. A. "The Strategic Impact of Information Technologies on Managerial Work." Prospectives for a Study (F-52), Center for Future Research, University of Southern California, September 1983.

Van Horn, R. L. "Empirical Studies on Management Information Systems." Data Base, Volume 5, 1973, pp. 172-180.

Vitalari, N. P. "The Need for Longitudinal Designs in the Study of Computing Environments." In E. Mumford et al., Editors, Research Methods in Information Systems, New York: North Holland, 1985, pp. 243-265.

Vogel, D. R., and Wetherbe, J. C. "MIS Research: A Profile of Leading Journals and Universities." Data Base, Volume 16, Number 1, Fall 1984, pp. 3-14.

Weick, K. E. "Theoretical Assumptions and Research Methodology Selection." In W. McFarlan, Editor, Information Systems Research Challenge, Harvard Business School Press, 1984, pp. 110-132.

Wood-Harper, A. J. "Research Methodology in Information Systems: Using Action Research." In E. Mumford et al., Editors, Reseanch Methods in Infonmation Systems, New York: North Holland, 1985, pp. 169-191.

\section{ENDNOTES}

1. In order to create some continuity, it was decided that only journals that have been in press for at least 10 years would be included. A few new academic MIS journals (Information Systems Research and Joumal of $M I S$ ) have emerged in recent years. Some others have been discontinued or merged with other journals (Human Affairs or Systems Objectives Solutions).

2. In cases where the coders felt that the article abstract was a good representation of content, the summary was based on the abstract. For the articles for which the abstract was not highly descriptive of the content, the summary was based on material from the article.

3. To calculate inter-coder reliability, a random sample of the articles were recoded twice during the coding process. Reliabilities of 71 percent and 70 percent were calculated, which are consistent with the commonly accepted criterion of 70 percent for this type of research.

4. In categorizing the articles, a distinction was made between a case study as a research methodology and an illustrative article that essentially uses exemplars for demonstrative purposes. 


\section{Appendix A}

\section{CLASSIFICATION SCHEME FOR ARTICLE TYPE}

\section{NON-EMPIRICAL ARTICLES}

\subsection{Conceptual Orientation}

\section{MIS Frameworks}

Propose a framework for defining the content and scope of MIS and provide directions for MIS research.

Sprague, R. H. "A Framework for the Development of Decision Support Systems." MIS Quarterly, Volume 4, Number 4 (December 1980), pp. 1-26.

Ives, B.; Hamilton, S.; and Davis, G. B. "A Framework for Research in Computer Based Management Information Systems." Management Science, Volume 26, Number 9 (September 1980), pp. 910-934.

\section{Conceptual Models}

Present an integrated, schematic representation of MIS-related behavior, activity, organization, method, structure, or process.

King, W. R. "Strategic Planning for Management Information Systems." MIS Quarterly, Volume 2, Number 1 (March 1978), pp. $27-37$.

Gibson, C. F., and Nolan, R. L. "Managing the Four Stages of EDP Growth." Harvard Business Review, Volume 52, Number 1 (January/February 1974), pp. 76-88.

\section{Conceptual Overviews}

Contain an overview of many concepts or theories in one or more areas and do not propound or support any individual theory, idea or approach.

DeSanctis, G. "Computer Graphics as Decision Aids: Directions for Research." Decision Sciences, Volume 15, Number 4 (October 1984), pp. 463-487.

Attewell, P., and Rule, J. "Computing and Organizations: What We Know and What We Don't Know." Communications of the ACM, Volume 27, Number 12 (December 1984), pp. 1184-1192.

\section{Theory from Reference Disciplines}

Present theory or theories drawn from outside the MIS field but applied within an MIS context.

Robey, D., and Taggart, W. "Human Information Processing in Information and Decision Support Systems." MIS Quarterly, Volume 6, Number 2 (June 1982), pp. 61-73.

Huber, G. P. "The Nature and Design of Post-Industrial Organizations." Management Science, Volume 30, Number 8 (August 1984), pp. 928-951.

Other

Conceptual orientation but not related to any organizational context. Mostly articles dealing with MIS education.

Couger, J. D. "Curriculum Recommendations for Undergraduate Programs in Information Systems." Communications of the ACM, Volume 16, Number 12 (December 1973), pp. 727-749.

Nunamaker, J. F.; Couger, J. D.; and Davis, G. B. "Information Systems Curriculum Recommendations for the 80's." Communications of the $A C M$, Volume 25, Number 11 (November 1982), pp. 781-805.

\subsection{Illustrative}

\section{Opinion and Example}

Give advice and guidance for practice/research, in the form of rules and recommendations, steps or procedures to be followed, hints and warnings. May be supported by examples and applications.

Keen, P. G. W. "Information Systems and Organizational Change." Communications of the ACM, Volume 24, Number 1 (January 1981), pp. 24-33.

Gerrity, T. P., and Rockart, J. F. "End-User Computing: Are You a Leader or a Laggard?" Sloan Management Review, Volume 27, Number 4 (Summer 1986), pp. 25-34. 


\section{Opinion and Author Experience}

Similar to Opinion and Example type, but also describe the author's experience in some relevant context (e.g., an MIS planning or system development project).

Matlin, G. L. "How To Survive a Management Assessment." MIS Quarterly, Volume 1, Number 1 (March 1977), pp. 11-17.

Leonard-Barton, D. "The Case for Integrative Innovation: An Expert System at Digital." Sloan Management Review, Volume 29, Number 1 (Fall 1987), pp. 7-19.

Tools, Techniques, Methods, Model Applications

Often highly specific and detailed, as well as technically or methodologically precise.

Rockart, J. F. "Chief Executives Define Their Own Data Needs." Harvard Business Review, Volume 57, Number 2 (March/April 1979), pp. 81-93.

Ahituv, N., and Igbaria, M. "A Model for Predicting and Evaluating Computer Resource Consumption." Communications of the ACM, Volume 31, Number 12 (1988), pp. 1467-1473.

1.3 Mixed

\section{Conceptual Frameworks and Their Applications}

Contain both conceptual and illustrative elements. Often present some conceptual model or framework and then describe an application of it.

Naumann, J. D., and Jenkins, A. M. "Prototyping: The New Paradigm for Systems Development." MIS Quarterly, Volume 6, Number 3 (September 1982), pp. 29-44.

McFarlan, F. W. "Information Technology Changes the Way You Compete." Harvard Business Review, Volume 62, Number 3 (May/June 1984), pp. 98-103.

\section{EMPIRICAL ARTICLES}

2.1 Objects

Description of individual or types of systems, products, installations, or IS departments.

Individual objects:

Hall, W. A., and McCauley, R. E. "Planning and Managing a Corporate Network Utility." MIS Quarterly, Volume 11, Number 4 (December 1987), pp. 437-449.

Bonczek, R. H.; Holsapple, C. W.; and Whinston, A. B. "Aiding Decision Makers with a Generalized Data Base Management System: An Application to Inventory Management." Decision Sciences, Volume 9, Number 2 (April 1978), pp. 228-245.

Types of object:

Johansen, R., and Bullen, C. "What To Expect From Teleconferencing." Harvard Business Review, Volume 62, Number 2 (March/April 1984), pp. 164-174

McHenry, W. K., and Goodman, S. E. "MIS in Soviet Industrial Enterprises: The Limits of Reform From Above." Communications of the $A C M$, Volume 29, Number 11 (November 1986), pp. 1034-1043.

\subsection{Events/Process}

\section{Laboratory Experiment}

Manipulate independent variable; control for intervening variables; controlled environment.

Alavi, M., and Henderson, J. C. "An Evolutionary Strategy for Implementing a Decision Support System." Management Science, Volume 27, Number 11 (November 1981), pp. 1309-1323.

Benbasat, I.; Dexter, A. S.; and Masulis, P. S. "An Experimental Study of the Human/Computer Interface." Communications of the ACM, Volume 24, Number 11 (November 1981), pp. 752-762.

\section{Field Experiment}

As for laboratory experiment, but carried out in a natural setting.

Franz, C.R; Robey, D.; and Koeblitz, R. R. "User Response to an Online Information System: A Field Experiment." MIS Quarterly, Volume 10, Number 1 (March 1986), pp. 29-42.

Barber, R. E., and Lucas, H. C. "System Response Time, Operator Productivity and Job Satisfaction." Communications of the ACM, Volume 26, Number 11 (November 1983), pp. 972-986. 


\section{Field Study}

No manipulation; measure independent and dependent variables; natural setting or environment; usually based on multiple observations via questionnaire.

Zmud, R. W. "Diffusion of Modern Software Practices: Influence of Centralization and Formalization." Management Science, Volume 28, Number 12 (December 1982), pp. 1421-1431.

Swanson, E. B. "Information Channel Disposition and Use." Decision Sciences, Volume 18, Number 1 (January 1987), pp. 131-145.

\section{Case Study} No variable manipulation, usually no pre-defined relationships among the variables of interest; no experimental design or controls, exploratory
in nature.

Single case studies:

Markus, M. L. "Power, Politics and MIS Implementation." Communications of the ACM, Volume 26, Number 6 (June 1983), pp. 430-444

Kling, R., and Iacono, S. "The Control of Information Systems Developments After Implementation." Communications of the ACM, Volume 27, Number 12 (December 1984), pp. 1218-1226.

Multiple case studies:

Olson, M. H. "Remote Office Work: Changing Work Patterns in Space and Time." Communications of the ACM, Volume 26, Number 3 (March 1983), pp. 182-187.

Boynton, A. D., and Zmud, R. A. "An Assessment of Critical Success Factors." Sloan Management Review, Volume 25, Number 4 (Summer 1984), pp. 17-27.

Survey

An exploratory field study; does not test relationships between variables.

Adams, C. "How Management Users View Information Systems." Decision Sciences, Volume 6, Number 2 (April 1975), pp. 337-345.

Gillenson, M. "Trends in Data Administration." MIS Quarterly, Volume 9, Number 4 (December 1985), pp. 317-325.

Development of IS Instruments

Describe the development of MIS instruments, measures or research tools.

Bailey, J. E., and Pearson, S. W. "Development of a Tool for Measuring and Analyzing Computer User Satisfaction." Management Science, Volume 29, Number 5 (May 1983), pp. 530-545.

Barki, H.; Rivard, S.; and Talbot, J. "An Information Systems Keyword Classification Scheme." MIS Quarterly, Volume 12, Number 2 (June 1988), pp. 299-322.

\section{Ex Post Descriptions}

Interest in reporting the results of the project develops after the project is complete (or is partially complete).

Kozar, K. A., and Mahlum, J. M. "A User Generated Information System: An Innovative Development Approach." MIS Quarterly, Volume 11, Number 2 (June 1987), pp. 163-174.

Hiltz, S. R, and Turoff, M. "The Evolution of User Behavior in a Computerized Conferencing System." Communications of the ACM, Volume 24, Number 11 (November 1981), pp. 739-751.

Other

Use a research methodology not covered above. Mostly based on secondary data (already collected by someone other than the researcher).

Dutton, W. H., and Kraemer, K. L. "Management Utilization of Computers in American Local Governments." Communications of the $A C M$, Volume 21, Number 3 (March 1978), pp. 206-218.

Mendelson, H. "Economies of Scale in Computing: Grosch's Law Revisited." Communications of the ACM, Volume 30, Number 12 (December 1987), pp. 1066-1072. 


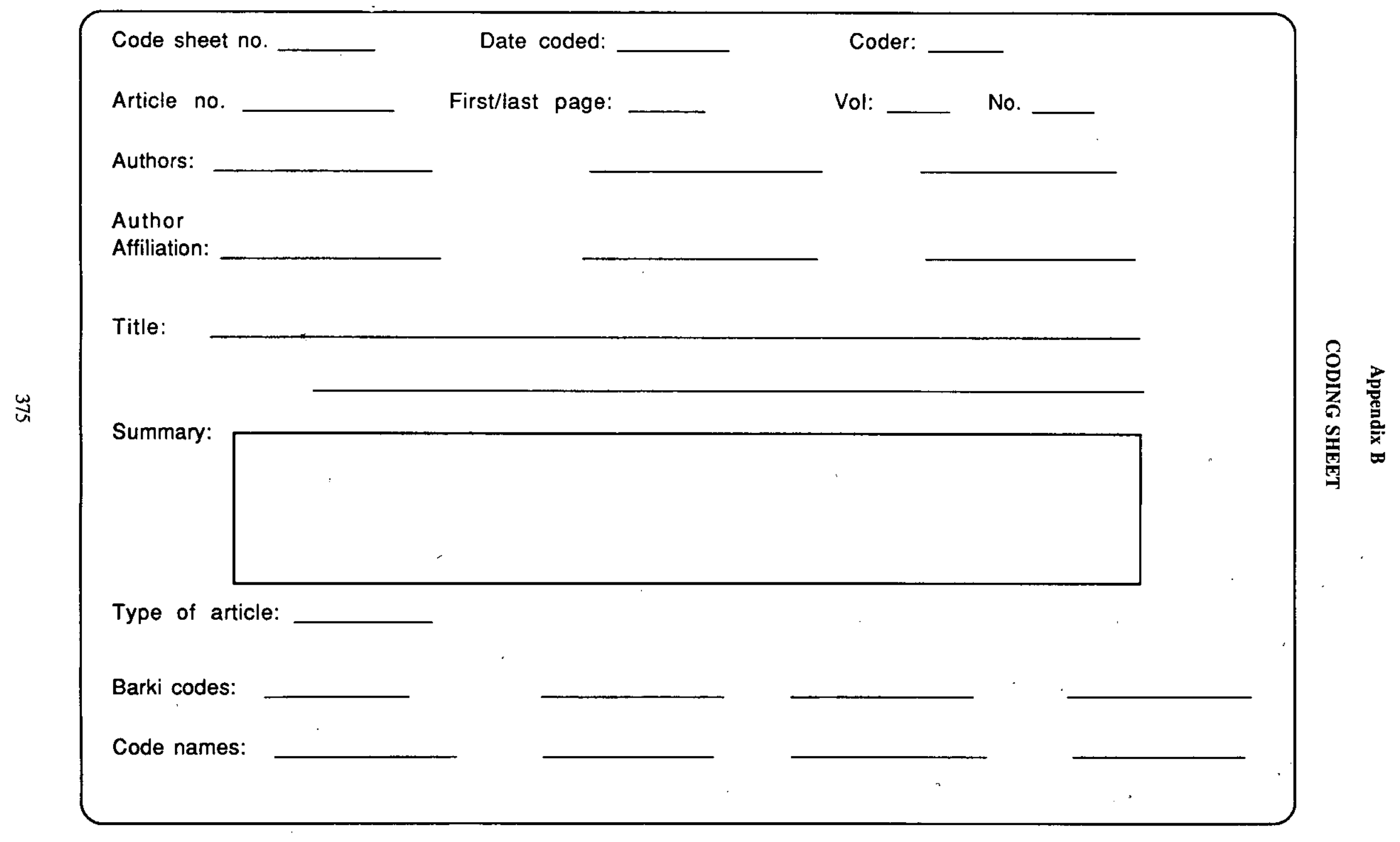

